\title{
IMPLEMENTASI ALGORITMA C5.0 UNTUK MENGANALISA GEJALA PRIORITAS PADA ANAK YANG MENGALAMI BULLYING
}

\section{Laporan Tugas Akhir}

Diajukan Untuk Memenuhi

Persyaratan Guna Meraih Gelar Sarjana Strata 1

Teknik Informatika Universitas Muhammadiyah Malang

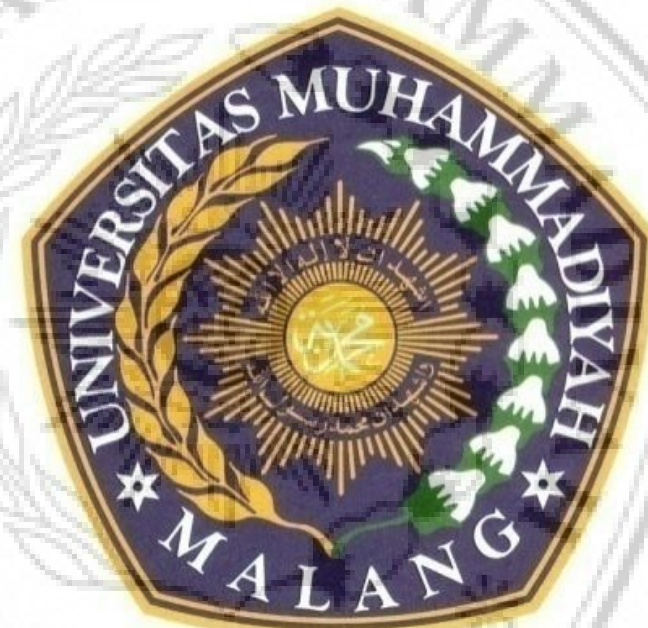

Nabillah Annisa Rahmayanti

(201410370311043)

\section{JURUSAN TEKNIK INFORMATIKA}

FAKULTAS TEKNIK

UNIVERSITAS MUHAMMADIYAH MALANG 


\section{LEMBAR PERSETUJUAN}

\section{IMPLEMENTASI ALGORITMA C5.0 UNTUK MENGANALISA}

GEJALA PRIORITAS PADA ANAK YANG MENGALAMI

BULLYING

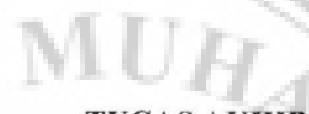

TUGAS AKHIR

\section{Diajukan Untuk Memenuhi}

Persyaratan Guna Meraih Gelar Sarjana Strata 1

Teknik Informatika Universitas Muhammadiyah Malang

Menyetujui,

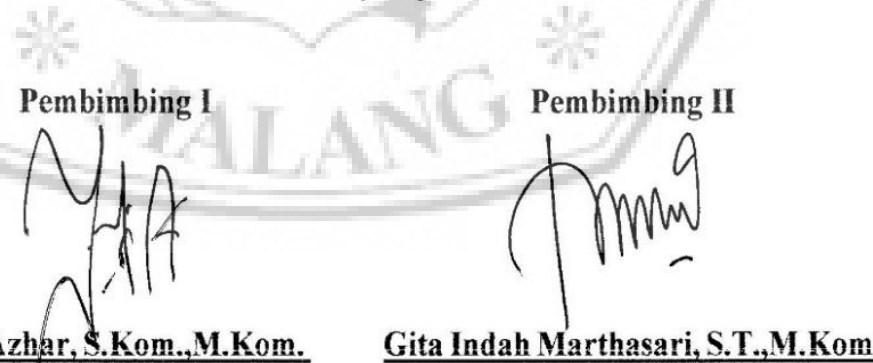

NIP.108.1410.0544

NIP.108.0611.0442 


\title{
LEMBAR PENGESAHAN
}

\section{IMPLEMENTASI ALGORITMA C5.0 UNTUK MENGANALISA \\ GEJALA PRIORITAS PADA ANAK YANG MENGALAMI \\ BULLYING}

\author{
TUGAS AKHIR
}

Sebagai Persyaratan Guna Meraih Gelar Sarjana Strata 1

Teknik Informatika Universitas Muhammadiyah Malang

Disusun Oleh

Nabillah Annisa Rahmayanti

201410370311043

Tugas Akhir ini telah diuji dan dinyatakan lulus melalui sidang majelis

penguji Pada tanggal

Menyetujui,

Penguji I

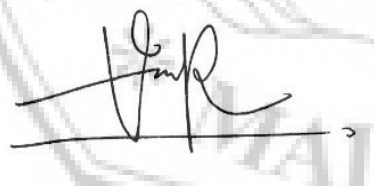

Penguji II

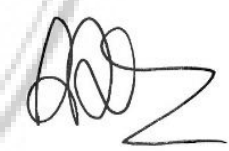

Mengetahui,

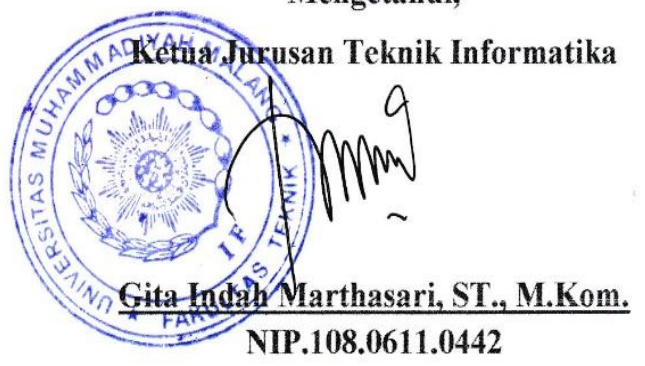




\section{LEMBAR PERNYATAAN}

Yang bertanda tangan di bawah ini :

$\begin{array}{ll}\text { NAMA } & : \text { Nabillah Annisa Rahmayanti } \\ \text { NIM } & : 201410370311043 \\ \text { FAK/JUR } & : \text { TEKNIK/INFORMATIKA }\end{array}$

Dengan ini saya menyatakan bahwa Tugas Akhir dengan judul "IMPLEMENTASI ALGORITMA C5.0 UNTUK MENGANALISA GEJALA PRIORITAS PADA ANAK YANG MENGALAMI BULLYING" beserta seluruh isinya adalah karya saya sendiri dan bukan merupakan karya tulis orang lain, baik sebagian maupun seluruhnya, kecuali dalam bentuk kutipan yang telah disebutkan sumbernya.

Demikian surat pernyataan ini saya buat dengan sebenar-benarnya. Apabila kemudian ditemukan adanya pelanggaran terhadap etika keilmuan dalam karya saya ini, atau ada klaim dari pihak lain terhadap keaslian karya saya ini maka saya siap menanggung segala bentuk resiko/sanksi yang berlaku.

Malang, 4 Oktober 2018

Yang Membuat Pernyataan

Nabillah Annisa Rahmayanti

Menyetujui,

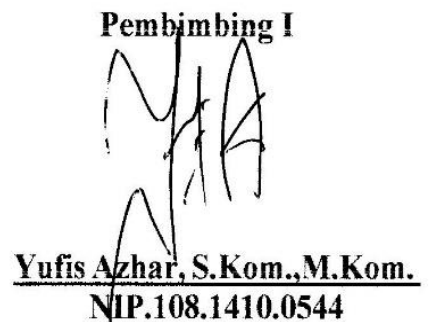

Pembimbing II

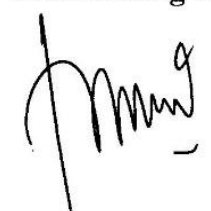

Gita Indah Marthasari, S.T.,M.Kom. NIP.108.0611.0442 


\section{LEMBAR PERSEMBAHAN}

Syukur Alhamdulillah atas kehadirat Allah SWT dengan limpahan hidayah dan rahmad-Nya, shalawat serta salam senantiasa tercurahkan kepada junjungan Nabi besar Rasulullah Muhammad SAW sang revolusioner. Tiada kata selain puji syukur dan terima kasih karena penulis dapat menyelsaikan Tugas Akhir ini. Oleh karena itu, dengan rendah hati penulis menyampaikan ucapan terima kasih yang sebesar-besarnya kepada:

1. Kedua orang tua tercinta Bapak Kasiyanto dan Ibu Nur Anim Muffaridah, serta kedua Kakak, yang senantiasa tanpa lelah mendo'akan dan memberi dukungan, semoga berkah dan rahmadNya selalu menyertai beliau setiap waktu;

2. Bapak Yufis Azhar, S.Kom.,M.Kom dan Ibu Gita Indah Marthasari, S.T.,M.Kom selaku dosen pembimbing dalam tugas akhir yang selalu membimbing dengan kesabaran dan mengarahkan pemahaman;

3. Ibu Gita Indah Marthasari, S.T.,M.Kom selaku Ketua Jurusan Teknik Informatika, Fakultas Teknik, Universitas Muhammadiyah Malang;

4. Bapak Denar Regata Akbi, S.Kom., M.Kom. selaku dosen wali kelas A angkatan 2014;

5. Bapak/Ibu Dosen Fakultas Teknik, Universitas Muhammadiyah Malang yang senantiasa menjadi pendidik tanpa tanda jasa;

6. Laki-laki spesial dalam hidup saya Mochamad Irfan yang selalu memotivasi dan menyemangati saya untuk segera menyelesaikan Tugas Akhir;

7. Sahabat-sahabat saya Nurma, Rizqika, Ulfie, Sandy, Naufal dan seluruh anggota grup APENGERS selaku support system;

8. Rekan seperjuangan saya dalam mengerjakan Tugas Akhir Nirmala Rizka Karim.

Semoga segala bantuan, motivasi, dan do'a yang diberikan kepada penulis diridhoi dan mendapat imbalan yang berlipat ganda dari Allah SWT. 


\section{KATA PENGANTAR}

Alhamdulillahirabbil'alamin, segala puji bagi Allah Subhanahu wa Ta'ala, atas segala limpahan rahmat, hidayah dan karunia-Nya sehingga penulis mampu menyelsaikan tugas akhir ini sebagai salah satu syarat menyelsaikan studi sarjana strata 1 di Teknik Informatika Universitas Muhammadiyah Malang. Salam dan shalawat kepada Rasulullah Muhammad Shallallahu 'Alaihi Wasallam, beserta para keluarga, sahabat dan para pengikutnya hingga akhir zaman. Semoga segala hal yang penulis lakukan berkaitan dengan skripsi ini juga bernilai ibadah di sisi Allah Subhanahu wa Ta'ala. Amin.

Segenap kemampuan penulis telah dicurahkan dalam penyusunan tugas akhir ini. Namun demikian, penulis sangat menyadari bahwa kesempurnaan hanya milik Allah SWT. Sebagai makhluk ciptaannya tentulah diri penulis memiliki banyak keterbatasan. Oleh karena itu, segala bentuk saran dan kritik konstruktif senantiasa penulis harapkan agar di kemudia hari tulisan ini menjadi lebih baik. Di akhir kata, penulis sangat berharap tulisan ini dapat bermanfaat di hari kemudian bagi ilmu pengetahuan ataupun mampu meski hanya sekedar menambah wawasan bagi siapapun yang membaca tulisan ini.

Malang, 12 Oktober 2018

Penulis 


\section{DAFTAR ISI}

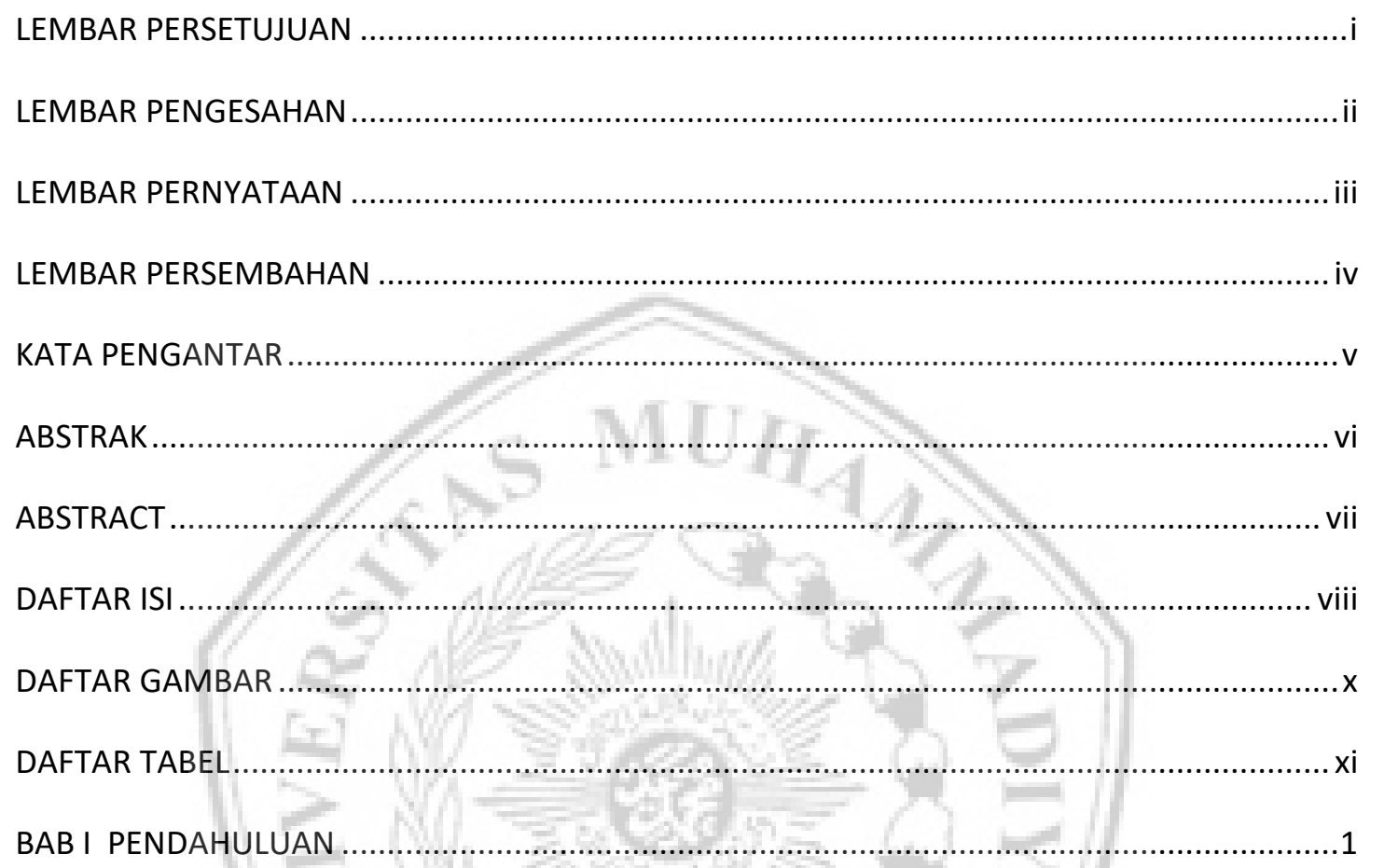

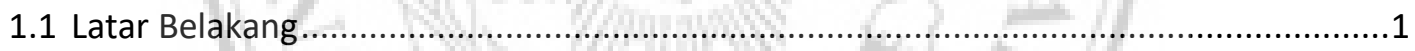

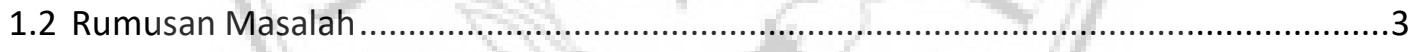

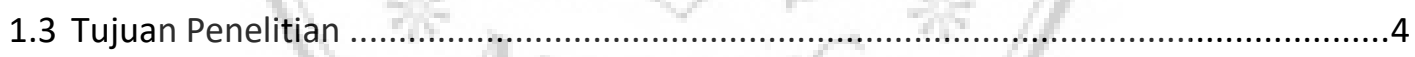

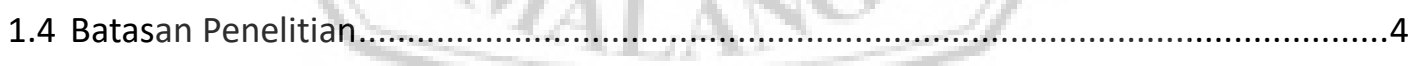

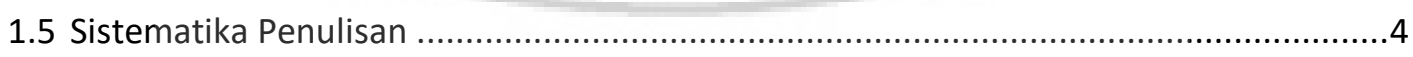

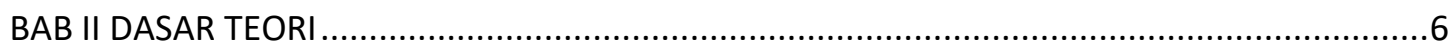

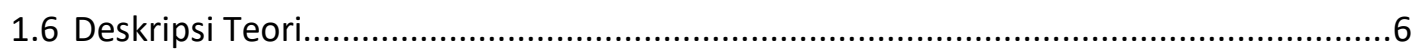

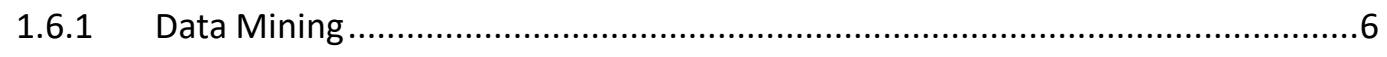

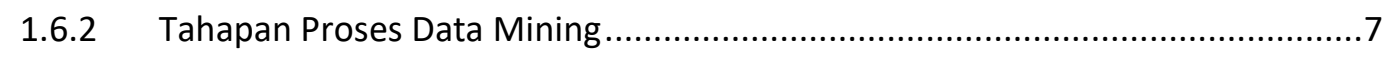

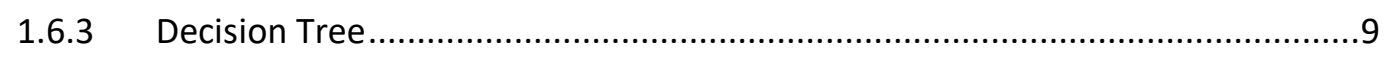

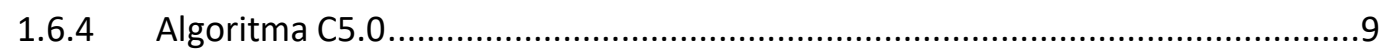

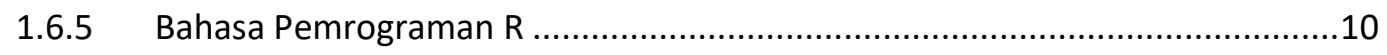


1.6.6 Penelitian Terkait ..................................................................

BAB III ANALISA DAN PERANCANGAN SISTEM.....................................................16

3.1 Dasar Penelitian ..................................................................................

3.2 Instrumen Penelitian ................................................................................. 16

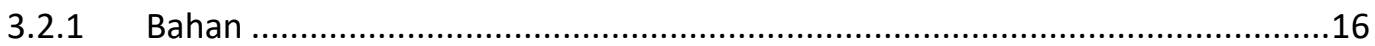

P.2.2 Peralatan ......................................................................................

3.3 Sumber Data ....................................................................................... 17

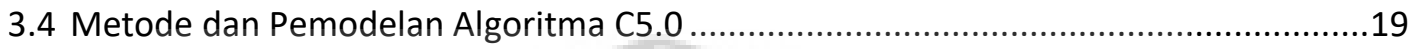

3.5 Tahapan Evaluasi Perhitungan Akurasi .....................................................23

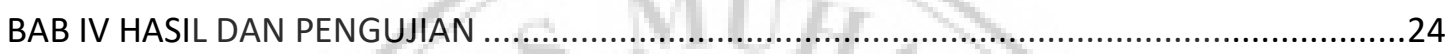

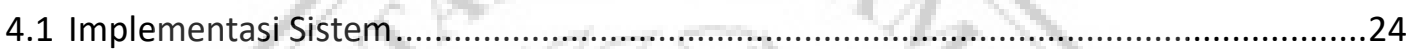

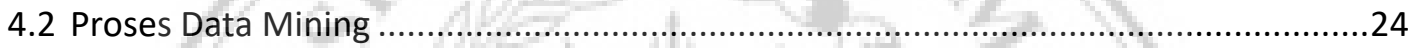

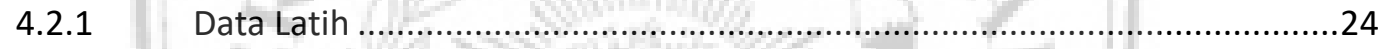

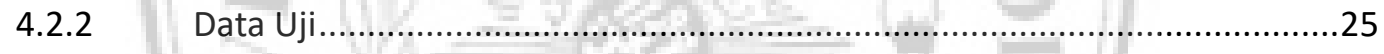

4.2.3 Implementasi Menggunakan Algoritma C5.0 ...................................26

Pengujian dan Validasi.................................................................27

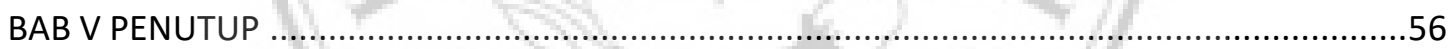

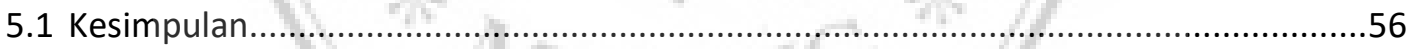

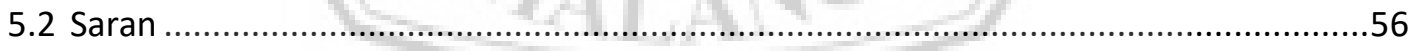

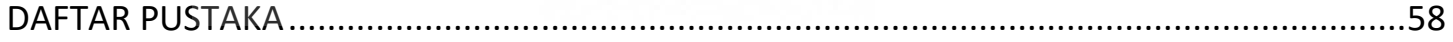

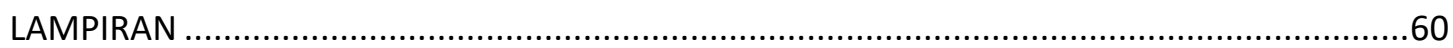




\section{DAFTAR GAMBAR}

Gambar 2.1 Tahapan Proses Data Mining[9] .......................................................... 7

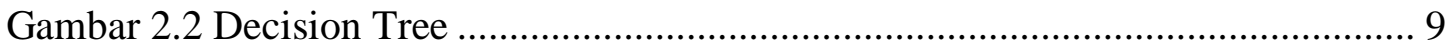

Gambar 3.1 Diagram Alir Tahap Menemukan Accuracy dan Confusion Matrix ....... 20

Gambar 3.2 Pemodelan Algoritma C5.0 …............................................................. 21

Gambar 4.1 Source Code Pemodelan dengan Algoritma C5.0 ................................. 26

Gambar 4.2 Skema Pembagian Data Testing Dengan Metode Cross Validation ....... 28

Gambar 4.3 Hasil Pengujian Pertama ..................................................................... 29

Gambar 4.4 Pohon Keputusan Pengujian Pertama ................................................... 30

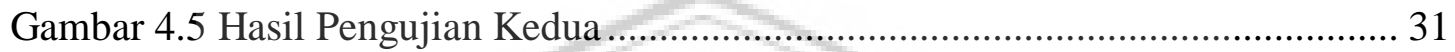

Gambar 4.6 Pohon Keputusan Pengujian Kedua ...................................................... 32

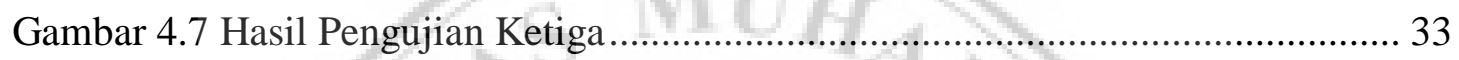

Gambar 4.8 Pohon Keputusan Pengujian Ketiga .................................................... 33

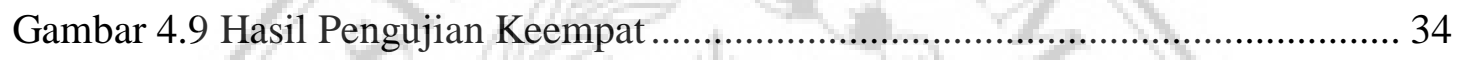

Gambar 4.10 Pohon Keputusan Pengujian Keempat ................................................ 35

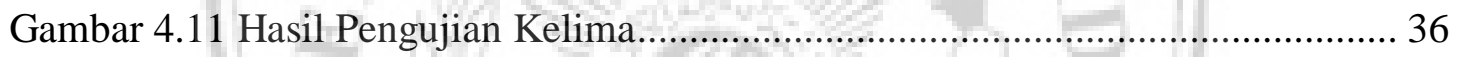

Gambar 4.12 Pohon Keputusan Penguian Kelima _.................................................. 37

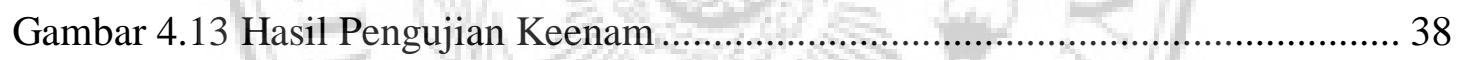

Gambar 4.14 Pohon Keputusan Pengujian Keenam .................................................. 39

Gambar 4.15 Hasil Pengujian Ketujuh.................................................................... 40

Gambar 4.16 Pohon Keputusan Pengujian Ketujuh................................................. 41

Gambar 4.17 Hasil Pengujian Kedelapan ............................................................... 42

Gambar 4.18 Pohon Keputusan Pengujian Kedelapan .............................................. 43

Gambar 4.19 Hasil Pengujian Kesembilan .............................................................. 44

Gambar 4.20 Pohon Keputusan Pengujian Kesembilan ........................................... 45

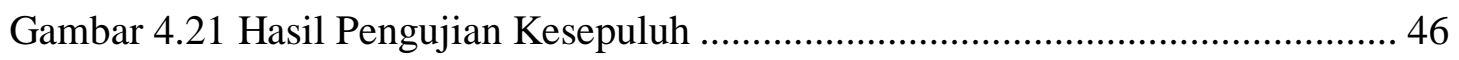

Gambar 4.22 Pohon Keputusan Pengujian Kesepuluh ............................................. 47

Gambar 4.23 Hasil Pengujian Seleksi Fitur ........................................................... 48

Gambar 4.24 Hasil Pengujian Algoritma Naive Bayes Dengan 54 Atribut................ 51

Gambar 4.25 Hasil Pengujian Algoritma Naive Bayes Dengan 19 Atribut................ 52

Gambar 4.26 Hasil Pengujian Algoritma KNN Dengan 54 Atribut ........................... 53

Gambar 4.27 Hasil Pengujian Algoritma KNN Dengan 19 Atribut ........................... 54 


\section{DAFTAR TABEL}

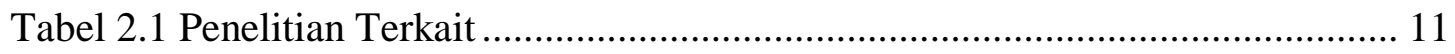

Tabel 2.2 Perbandingan Penelitian Terdahulu Dengan Penelitian Sekarang .............. 13

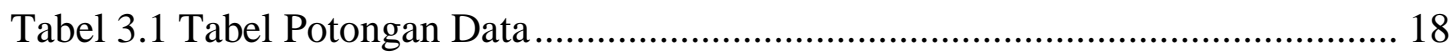

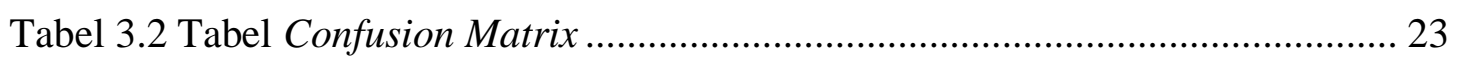

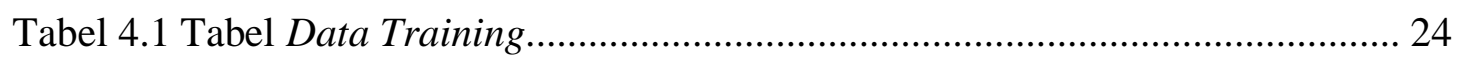

Tabel 4.2 Tabel Data Testing ................................................................................ 25

Tabel 4.3 Tabel Perhitungan Confusion Matrix ....................................................... 49

Tabel 4.4 Tabel Hasil Perhitungan Akurasi Skema Pengujian Cross Validation ....... 50

Tabel 4.5 Tabel Hasil Perbandingan Nilai Akurasi Dengan Pengujian 54 Fitur ........ 55

Tabel 4.6 Tabel Hasil Perbandingan Nilai Akurasi Dengan Pengujian 19 Fitur ........ 55 


\section{DAFTAR PUSTAKA}

[1] P. Ppds, P. F. K. Unair, S. P. Departemen, S. M. F. Psikiatri, F. K. Unair, and P. Ii, "Dokter, Peserta PPDS I Psikiatri FK UNAIR/RSUD Dr.

Soetomo, Peneliti I ** Psikiater, Konsultan, Staf Pengajar

Departemen/SMF Psikiatri FK UNAIR/RSUD Dr. Soetomo, Peneliti II *** Dokter, Staf Pengajar Ilmu Kesehatan Masyarakat FK UNAIR Surabaya, Konsultan ," pp. 1-11.

[2] B. Okeke-oti, "Page 1 1," System, pp. 3-4, 2010.

[3] A. L. B. Masalah, "No Title," pp. 1-7, 2011.

[4] E. S. Wahyuni, F. T. Industri, P. Studi, T. Elektro, U. I. Indonesia, and N. Bayes, "Penerapan metode seleksi fitur untuk meningkatkan hasil diagnosis kanker payudara," vol. 7, no. 1, pp. 283-294, 2016.

[5] B. N. Sari, "IMPLEMENTASI TEKNIK SELEKSI FITUR INFORMATION GAIN PADA ALGORITMA KLASIFIKASI MACHINE LEARNING UNTUK PREDIKSI PERFORMA AKADEMIK SISWA," pp. 6-7, 2016.

[6] K. P. Wirdhaningsih, D. E. Ratnawati, U. B. Malang, D. Mining, and D. Tree, "Penerapan Algoritma Decision Tree C5.0 Untuk Peramalan Forex," pp. 1-6, 2012.

[7] C. Cermat, S. Smp, and N. W. Tingkat, "Algoritma C4 . 5 Untuk Klasifikasi Calon Peserta Lomba," no, 24, pp. 1-6.

[8] J. Han, M. Kamber, and J. Pei, Data Mining: Concepts and Techniques. 2012.

[9] F. Gorunescu, Data Mining: Concepts and Techniques, vol. 12. 2011.

[10] I. Pramudiono, "Pengantar Data Mining: Menambang Permata Pengetahuan di Gunung Data," Kuliah Umum Ilmu Komputer.com, pp. 1-4, 2003.

[11] A.Budiarti, "Naive Bayes," Apl. dan Anal. Lit. Fasilkom UI, pp. 4-25, 2006.

[12] A. Max, S. Weston, and M. Culp, "Package 'C50,"” pp. 1-13, 2018.

[13] G. P. L. Edition, U. C. I. K. D. D. Archive, and I. Core, "Is See5 / C5 . 0 Better Than C4 . 5 ?,” pp. 4-6, 2018.

[14] B. A. B. Ii and L. Teori, "No Title,” pp. 4-12.

[15] R. Pandya and J. Pandya, "C5.0 Algorithm to Improved Decision Tree with Feature Selection and Reduced Error Pruning," Int. J. Comput. Appl., vol. 
117, no. 16, pp. 18-21, 2015.

[16] W. Budiharto and R. N. Rachmawati, "Pengantar Praktis Pemrograman R," pp. 3-13, 2013.

[17] P. S. Ke et al., "Fakultas Teknik - Universitas Muria Kudus 823," pp. 823829, 2017.

[18] B. Metode, P. Kuantitatif, and K. Dan, "Sugiyono Metode Penelitian Kuantitatif Kualitatif Dan R D DOWNLOAD,” 2017.

[19] "TABEL PENENTUAN JUMLAH SAMPEL ISAAC DAN MICHAEL DARI POPULASI TERTENTU DENGAN TARAF KESALAHAN $1 \%, 5$ $\%$, DAN $10 \%$ Sumber : Sugiyono, Metodologi Penelitian Pendidikan ( Pendidikan Kualitatif, Kuantitatif, dan R \& D ), ( Bandung: Alfabeta, 2010 ), hlm . 128 . DAFTAR NAMA RESPONDEN PENELITIAN,” 2010.

[20] J. Heridiansyah, "Pengaruh Advertising Terhadap Pembentukan Brand Awareness Serta Dampaknya Pada Keputusan Pembelian Produk Kecap Pedas ABC ( Studi Kasus Pada Konsumen Pengguna Kecap Pedas ABC di Kota Semarang ) Abstrak," vol. 4, no. 2, pp. 53-73, 2012.

[21] U. Auckland, "II Software R dan Fitur-Fiturnya," pp. 5-9.

[22] F. I. Komputer, U. Dian, and N. Semarang, "Klasifikasi Kelayakan Kredit Calon Debitur Bank Menggunakan Algoritma Decision Tree C4 . 5 Classification of Debitor 'S Bank Creditworthiness," pp. 1-12, 2014.

[23] D. Sugianti and M. A. Al Karomi, "Peningkatan Akurasi Algoritma KNN dengan Seleksi Fitur G ain Ratio untuk Klasifikasi Penyakit Diabetes Mellitus," 2009.

[24] M. A. Alkaromi and L. Belakang, "Komparasi Algoritma Klasifikasi untuk dataset iris dengan rapid miner Abstrak Pendahuluan," no. 285. 